\title{
The Ethics of Publication in Public Health
}

\author{
Selena Gray, BSc, MBCHB, MD, FFPH, FRCP ${ }^{1,2}$
}

\begin{abstract}
Publication in peer-reviewed journals is a key part of advancement in science and a vital part of development of the scientific basis for public health practice. The process of publication should promote rigorous standards of high quality ethical research and the wide dissemination of their findings. When considering the issues arising from publication in public health, relevant frameworks include those from the field of publication ethics, public health practice and epidemiological research.

The consequences of poor, or frankly fraudulent science, can have a substantial adverse impact both on health, and on the use of resources, and public credibility because of the population based nature of public health interventions. Professional and scientific journals therefore have a critical role in promoting and preserving the highest possible ethical and professional standards to advance the field of public health practice.

I present here a personal view of some of these ethical issues, predominantly from the perspective of an experienced editor, but also to some extent that of reviewers and of course, the authors.
\end{abstract}

Key Words: Ethics, public health, journals, publication, peer review

Suggested Citation: Gray S. The ethics of publication in public health. Public Health Reviews. 2012;34: epub ahead of print.

\section{INTRODUCTION}

Journal editors make decisions every day about what articles to publish, and what to commission. These decisions are strongly influenced by value judgments about what they perceive to be important and relevant to their field. Where then do ethics come into this? The definition of ethics according to the Oxford Dictionaries is "the moral principles that govern a person's behaviour or the conducting of an activity" or the "branch of knowledge that

\footnotetext{
${ }^{1}$ Professor, University of West of England, Bristol, UK.

${ }^{2}$ Deputy Postgraduate Dean, Severn Deanery, Bristol, UK.
}

Corresponding Author Contact Inormation: Selena Gray at selena.gray@uwe.ac.uk; Faculty of Health and Life Sciences, University of West of England, Glenside Campus, Blackberry Hill, Bristol, UK BS16 1DD. 
deals with moral principles". ${ }^{1}$ In this paper I will consider the first meaning, and will address this both from the perspective of the journal editor him or herself, and secondly from that of the editor dealing with authors.

\section{RELEVANT ETHICAL FRAMEWORKS}

A short overview of existing ethical frameworks from the field of peer review publication, public health practice and epidemiological research is given below.

\section{Peer-reviewed publications}

The Committee on Publication Ethics (COPE), (an international organisation based in the UK) produce comprehensive guidance for editors and publishers of peer-reviewed journals. In 2011, they published updated guidance, the Code of Conduct and Best Practice Guidelines for Journal Editors. ${ }^{2}$ A summary of the general duties of editors are shown in Table 1.

\section{Table 1}

General Duties and Responsibilities of Editors.

1. Editors should be accountable for everything published in their journals.

This means the editors should:

2. strive to meet the needs of readers and authors;

3. strive to constantly improve their journal;

4. have processes in place to assure the quality of the material they publish;

5. champion freedom of expression;

6. maintain the integrity of the academic record;

7. preclude business needs from compromising intellectual and ethical standards;

8. always be willing to publish corrections, clarifications, retractions and apologies when needed.

Source: Code of Conduct and Best Practice Guidelines for Journal Editors. COPE 2011. ${ }^{2}$

The World Association of Medical Editors (WAME) ${ }^{3}$ is an international nonprofit voluntary association of editors of peer-reviewed medical journals from countries throughout the world who seek to foster international cooperation among and education of medical journal editors and also issues guidelines for good practice. Notably in 2009, the WAME Editorial Policy and Publication Ethics Committees issued a statement about conflicts of interest in publication in peer-reviewed medical journals. ${ }^{4}$ 


\section{Public health practice}

A number of ethical frameworks have been developed to support public health professionals and policymakers. A sytematic review by ten Have, et al., ${ }^{5}$ identified six frameworks: Kass, ${ }^{6}$ Childress, et al., ${ }^{7}$ the Public Health Leadership Society, ${ }^{8}$ all of which focus on public health policy in the United States; the Nuffield Council on Bioethics framework, ${ }^{9}$ which particularly explores a model of appropriate intervention from the United Kingdom; the European Public Health Ethics Network (EUROPHEN) framework, ${ }^{10}$ which concentrates on public health policy in Europe; and Tannahill's framework, ${ }^{11}$ which is directed at the area of public health, health promotion and health improvement. Most of them provide a set of values or principles that serve as a standard for evaluating policy. Moreover, most frameworks articulate both the positive ethical foundations for public health and ethical constraints or concerns.

\section{Epidemiological research}

Coughlin ${ }^{12}$ summarises existing ethics guidelines for epidemiologists, recognizing that epidemiological research produces different ethical issues from clinical research, particularly with respect to the communities and participants who take part in research. Particular issues he identifies relate to: minimizing risks and providing benefits; avoiding and disclosing conflicts of interest; obligations to communities; informed consent; privacy and confidentiality; and ensuring proposals are subject to appropriate ethical review. Other more generic issues in these guidelines relate to scientific misconduct, intellectual property and data sharing, publication of research findings, and cross-cultural or international health research. These complement national guidelines for clinical research issues by organisations such as the Medical Research Council in the UK, ${ }^{13}$ and the National Institutes of Health in the US. ${ }^{14}$

\section{PRESSURES ON EDITORS}

Editors are subject to competitive pressures as they want their journal to succeed in what are often crowded fields. Depending on the journal, it will be run as a commercial venture, often by a large multinational company which may have other commercial interests, or as a specialist society journal, sponsored by that society and subsidized by membership income. Many society journals are supported by not-for-profit publishers. Irrespective of the source of funding, editors will want their journal to be successfuland to be seen as such. 


\section{Maximising the Impact Factor}

The overarching metric of success in most contexts is seen to be the Journal Impact Factor-this is "a measure of the frequency with which the "average article" in a journal has been cited in a particular year or period. The annual Journal Citation Reports (JCR) impact factor is a ratio between citations and recent citable items published." ${ }^{15}$ Clearly, this is not the only measure of success; reputation, ability to attract high profile authors, high circulation figures, appeal and wide dissemination to the target audience (which may not be primarily academic), and making a profit are other key factors. However, some of these are intrinsically linked to the impact factor as explored further below.

The impact factor allows journals to compare their "performance" directly with each other. Journals with a high impact factor are considered more prestigious, may count more favourably for academics in career terms, and will therefore attract more submissions of higher quality. As a result, there are considerable pressures on journal editors to develop editorial strategies that maximize their impact factor.

In general terms, relevant, rigorous research of better quality will tend to be cited more frequently, and thus editorial strategies that look for quality and relevance in the given field will be likely to be cited more frequently, and to drive up the impact factor. However, there can also be potential distorting factors. Papers that have a large number of references to articles already published in their journal ("self-citation") will also drive up the citation rates.

Publishing a highly controversial paper can result in high citation levels. This was demonstrated when the Lancet published the original paper by Andrew Wakefield in $1998^{16}$ linking measles, mumps and rubella (MMR) vaccine, later partially retracted by the Lancet ${ }^{17}$ and finally fully retracted in $2010 .^{18}$ This paper, and the subsequent media furore led to a dramatic decline in uptake rates in the MMR vaccine in the UK, with vaccination rates falling to 80 percent in 2003-2004. ${ }^{19}$ They are still below the 95 percent level recommended by the World Health Organization to ensure herd immunity, and in 2008, for the first time in 14 years, measles was declared endemic in England and Wales. Subsequent investigation by the $B M J$ and investigative journalist Brian $\operatorname{Dee}^{20}$ demonstrated that Andrew Wakefield was guilty of falsification of data; not one of the 12 cases reported in the 1998 Lancet paper was free of misrepresentation or undisclosed alteration, and in no single case could the medical records be fully reconciled with the descriptions, diagnoses, or histories published in the journal. After a 217 day hearing by the UK General Medical Council (GMC), it was concluded that he was guilty of dishonesty concerning the 
study's admissions criteria, its funding by the Legal Aid Board, and his statements about it afterwards and his name was erased from the medical register. ${ }^{21}$ However, the co-authors in this study did not escape without blame. Despite the clear finding of the GMC panel that it was Wakefield alone who wrote the final version of the paper, with his coauthors being unaware of which child was which in the paper's patient anonymised text and tables, they clearly failed in their duties as authors. The Lancet did not escape unscathed either, with many believing the journal should have retracted the paper much earlier.

Conversely, some important articles may not appear to have significant potential for citation. Public health issues of importance in low and middle income countries may not immediately be attractive to editors, due to the lack of potential for citation - there are fewer authors in those countries who are publishing, and therefore likely to cite the articles. Research done in relatively small countries newly acceded to the European Union may struggle to find an audience. Many journal editors are keen to support young doctors, graduates from master's programmes or those training in the public health professions to publish in journals, but may be concerned about the effect of these (usually small research projects) on the journals profile. To escape the dominance of high income country publications, it may be necessary to establish specialist journals in lower and middle income countries.

A particular dilemma occurs when a submission is in an important area in public health terms, but may have a relatively weak design, or low response rate, and a judgment has to be made as to whether this still constitutes a relevant contribution to the field - this can be the case in the area of public health interventions, where field work is challenging. One example might be where a survey has a response rate that is low in conventional terms but is addressing an important health issue, such as a study of second hand exposure to tobacco in casino workers that demonstrated respiratory symptoms in 84 percent of those surveyed, ${ }^{22}$ appreciably higher than that reported in studies of bar workers, and contributed to the policy debate as to whether this high risk group of workers should be excluded from tobacco-free legislation.

In contrast, there may be perfectly designed epidemiological studies that are scientifically robust, but add little to our understanding of how to improve public health, or where findings are statistically significant, but appear to have little public health impact or relevance. Judging if these warrant publication can be challenging.

Increasingly important is the consideration of external validity, particularly important in more applied fields of research such as public health, where we are particularly interested in knowing if programmes effective in one situation will work in other settings or with other populations. Steckler, 
et al. ${ }^{23}$ have highlighted the role that journal editors can play, not only in promoting high standards of reporting of characteristics relating primarily to the internal validity of research such as the Consolidated Standards of Reporting Trials (CONSORT) Statement ${ }^{24}$ for randomised controlled trials, and the Preferred Reporting Items for Systematic Reviews and MetaAnalyses (PRISMA) Statement for sytematic reviews, ${ }^{25}$ but also for external validity, by ensuring that authors include key details pertaining to these issue. These are shown in Table 2.

Table 2

Reporting information required to consider External Validity of studies

1. Study participant recruitment and selection procedures, participation rates, and representative nature at the levels of individuals, intervention staff, and delivery settings.

2. Level and consistency of implementation across program components, settings, staff, and time.

3. Impact on a variety of outcomes, especially those important to populations, practitioners, and decision makers (e.g., quality of life, program costs, and adverse consequences).

4. Follow-up reports should include attrition at all levels in item 1, long-term effects on outcomes in item 3, and program sustainability, modification, or discontinuance.

Source: Steckler, et al. $2008 .^{23}$

\section{Negative findings}

A particular challenge relates to those studies which demonstrate negative findings - important but "boring"- - less likely to excite their audience, and less likely to attract large number of citations but critically important. Evidence suggests that authors are less likely to write up negative research findings and submit them for publication, and even when they do so, they take longer to be published and are more likely to be published in low impact or more difficult to access journals. ${ }^{26}$ Early hypothesis-generating research may be given a high profile and much publicity, later refuted by more robust epidemiological research that receives little attention from the media or the profession. A classic example is that of vitamin $\mathrm{K}$ injections, where case-control studies in the 1990s suggested a possible link between vitamin $\mathrm{K}$ injections and childhood leukaemia. This was followed by studies in the UK, across Europe, and in the US, which found no association. However, the controversy caused public concern about a highly effective intervention to prevent vitamin K deficiency bleeding (VKDB) in babies. ${ }^{27}$ The role of the editors in accepting papers that identify potential (but unproven) public health risks and harms versus the potential damage and loss of confidence in effective interventions can be a difficult balance. 
A further example of a publication of a paper that fell into the category of important but dull —and that was potentially considered "too unsurprising, or too radical in its threat to established interests or, paradoxically, both" 28 was a paper which modeled the effectiveness of screening for future cardiovascular disease using age alone compared to multiple risk factors and age. ${ }^{29}$ This paper concluded, counterintuitively, that simply using age was as effective as more complicated screening methods using serum cholesterol and blood pressure. Smith ${ }^{28}$ describes how the publication of this paper took over two years, required 24 different reviewers, and yet concludes that although the final version that was ultimately published is different, the central message - that age alone is as good as complex risk assessment was fundamentally unchanged. Smith urges us to consider if we should "scrap" pre-publication review and concentrate instead on post-publication review.

\section{Parochialism}

Another tension can relate to the audience for the journal; how parochial should a journal be? If the main focus is for example on UK public health practice will including more international articles alienate the core audience? This may be a concern in perpetuating a north-south divide in the publishing literature which then exacerbates the already significant gap in funding for research between the developed and developing world. This has been termed the "10/90 gap" by the Global Forum for Health Research ${ }^{30}$ based on data which shows that there is a gross imbalance between the funding for health research applied to the health problems of low and middle income countries and the burden of preventable disease found there. Public health is clearly a global discipline, and we must learn to take evidence derived in one setting and apply it to others. However, evidence may be interpreted differentlyor extra weight given - as is evident in the differing policies regarding folic acid food fortification of food in the US and Europe. Folic acid food fortification has been mandatory in the US since 1996 and has been associated with a 25 percent reduction in neural tube defects, ${ }^{31}$ in Canada since 1998 and recommended and subsequently in over 60 countries - but still not implemented in the UK since 2009, nor yet in any European country, except Kazakhstan.

\section{Conflicts of Interest}

Other key issues with respect to journals relate to advertising and sponsorship and the potential for this to distort editorial decision-making. Although in general the potential for commercial sponsorship in the world of public health journals is much more limited as compared to major medical journals, particularly with respect to pharmaceutical products, it remains a concern. 
The recent exposé published in the $B M J^{32}$ examining the growth of sports drinks, graphically outlined the interdependency of commercial sponsorship, sports medicine journals, academics and editorial committee membership that together promoted the belief that sports drinks were essential for essential hydration in any sort of physical activity. Another area of public health practice where there has been considerable concern that commercial interests have had an undue influence is pandemic influenza. As outlined by Cohen, ${ }^{33}$ decisions made within the WHO led to national governments committing funds equivalent to millions of British Pounds to buy anti-virals and vaccines during the $2009 \mathrm{H} 1 \mathrm{~N} 1$ influenza pandemic. WHO has conceded that the arrangements they have include effective mechanisms to deal with conflicts of interest. ${ }^{34}$ However, Evans ${ }^{35}$ concludes that whilst some have proposed that the pharmaceutical industry manipulated a fake pandemic, the real issue is a lack of processes for dealing with conflict of interest. Undoubtedly, issues of selective publication have played a key part in the evidence base for the anti-viral drug oseltamivir (Tamiflu ${ }^{\circledR}$ ); an updated Cochrane Review ${ }^{36}$ has concluded that it is not possible to draw conclusions about its effect on complications or transmission as full clinical study reports are unavailable to them.

A particular concern in the field of public health has been the pernicious influence of the tobacco industry in sponsoring, frequently covertly, research which has aimed to confuse or obfuscate key findings linking second hand exposure to tobacco to adverse impacts on health. ${ }^{37}$ This raises issues about how explicit conflicts of interest are, and in particular whether journals should have a blanket policy to not accept any articles from sources with any connection to the tobacco industry. Whilst some journals have a set policy of not accepting articles from certain sources, others consider each case on its merit, and require full disclosure of any commercial links, although policing this is difficult. However, editors always need to be aware of potential bias arising from conflicts of interest from funders; this can arise not only from those with a commercial interest such as pharmaceutical, food and beverage companies, but also from government or non-governmental organisations keen to prove by evaluative research that their interventions or policies are cost-effective.

One area that has proved challenging to a number of journal editors is where the organization hosting the journal has other commercial interests that are seen to be in direct ethical opposition to those espoused by the journal. This direct contradiction was illustrated by the global company Reed Elsevier, which publishes many medical and public health journals, including the Lancet, and at the same time was also promoting arms sales 
across the world. ${ }^{38}$ This led to a campaign ${ }^{39}$ by academics and doctors for Reed Elsevier to divest themselves of this part of their business, which they duly did in 2007. However, there is now a new movement and campaign, focused particularly on Elsevier, that is calling for a boycott of the company because of its business practices. There is concern that commercial publishers make profits based on the free labour of academics and subscription fees from their institutions' libraries, for a service that has become largely unnecessary, and that they actively support measures that limit the free transfer of information and research findings. ${ }^{40}$

The rise of open access publishing is in part underpinned by an ethical belief that research is a public good and an increasing number of influential research funders now require that there should be unrestricted access to the published output of research. In addition, a number of publishers, make their journals free to those in selected low income countries, promoting dissemination to those who might not otherwise afford them.

In his book, The Trouble with Medical Journals, ${ }^{41}$ Richard Smith, the former editor of the $B M J$, explored the issues of conflicts of interest in depth, and highlights the complex links and ties between major medical journals and the pharmaceutical industry, and how these can work together against the public interest.

\section{Table 3}

\section{Essential Tensions in Journal Editing}

Ensuring a balance between:

- Underrepresented topics and timely results.

- Coherent theme and diversity of topics.

- Practice and research.

- Historical and current content.

- Social science and biomedical science.

- Debate and evidence.

- External and internal funding.

- Commissioned and unsolicited contributions.

- Editorial review and peer review.

- Images and text.

Source: Northridge, et al. 2004. ${ }^{43}$ 


\section{Editorial Freedom}

The counterside to conflicts of interest is the notion of editorial freedom; as outlined by WAME": "Editors-in-chief should have full authority over the editorial content of the journal, generally referred to as "editorial independence." Owners should not interfere in the evaluation, selection, or editing of individual articles, either directly or by creating an environment in which editorial decisions are strongly influenced." The need to reaffirm this independence, and to maintain a clear line of separation between the journal and its owner-in this case a professional association, was eloquently made by Northridge, et al. ${ }^{42}$ with respect to the American Journal of Public Health in 2005. In an earlier article Northridge, McLeroy and Haviland ${ }^{43}$ coherently described a list of ten essential tensions in editing a journal, including the need to balance under-represented topics, with coherence and scientific quality and engendering critical debate (Table 3 )

\section{Peer reviewers}

Peer reviewers are a fundamental part of the system, yet this work is generally unremunerated and unrecognized. It can be difficult to identify reviewers who are willing to give the considerable time and energy needed for critiquing and usually improving submitted papers. Journals endeavor to recognize reviewers though the publication of reviewers, letters of thanks and other gestures, but ultimately are very dependent on people's willingness to give their time and to contribute to what they see as a public good or professional duty. Another dilemma can relate to the choice of peer reviewers. Should you select those recommended by the authors? Or others? Should peer review be anonymous or would it be better to know who provided feedback?

Will those working in a similar field be well placed to review an article or more likely to be highly critical as they are potentially direct competitors? A number of editors have attempted to improve the consistency and quality of peer review by developing detailed guidance aimed at those undertaking this activity. ${ }^{44-46}$

\section{Authorship and Plagiarism}

Editors need to be aware that the pressures to publish on academics are pervasive. Ensuring that all authors have contributed to the work, and are able to defend authorship is done through submission processes that require statements to be made and signed on these issues, but to some extent editors have to take at face value these declarations. Another area where editors can get drawn into disputes is where the authors cannot agree on authorship, or disagree about the order, or inclusion of one of more. In general these are 
referred back to the authors to resolve. The Committee on Publication Ethics $\mathrm{COPE}^{2}$ is a forum for editors and publishers of peer-reviewed journals to discuss all aspects of publication ethics and provides useful advice in these cases.

Plagiarism is when somebody presents the work of others (data, words or theories) as if they were his/her own and without proper acknowledgment. This can result in authors submitting similar papers to journals at the same time, or submitting minor variants of work to different journals. ${ }^{47}$ Although these types of issues are becoming easier to detect with the search facilities of the World Wide Web, they can be very difficult to detect, and often depend on the thoroughness of reviewers and editors, together with a modest index of suspicion. Examples of plagiarism given by COPE include individuals plagiarising others work (both published and unpublished from doctoral theses), submitting duplicate publications (self plagiarism), and plagiarising reviewer's work.

\section{Research misconduct}

The area of research misconduct is extremely difficult and requires close work between institutions and editors who may suspect misconduct. The potential damage from research misconduct has already been highlighted by the case of Andrew Wakefield. Detecting misconduct demands vigilance, and acting on concerns requires collaboration between both institutions and editors, both of whom have potentially much to lose. Different countries have different arrangements to deal with research misconduct and there is a call for UK research funders and others to do more to tackle research misconduct. ${ }^{48}$ However, editors have a key role to play as outlined by COPE (Table 4).

\section{Table 4}

\section{Duties relating to research and publication misconduct for editors}

Publish the contact details of their editor-in-chief who should act as the point of contact for questions relating to research and publication integrity;

Inform institutions if they suspect misconduct by their researchers, and provide evidence to support these concerns;

Cooperate with investigations and respond to institutions' questions about misconduct allegations;

Be prepared to issue retractions or corrections (according to the COPE guidelines on retractions) when provided with findings of misconduct arising from investigations;

Have policies for responding to institutions and other organizations that investigate cases of research misconduct.

Source: Wager, 2012.49 


\section{CONCLUSION}

Editing a peer-reviewed public health journal is an enormous privilege. It brings with it ethical responsibilities and challenges, some of which have been highlighted in this article. Publication in peer-reviewed journals remains a key method for establishing and progressing the evidence base for public health practice and providing tools for policy development and implementation. Editors must remain vigilant to avoid allowing external drivers to distort their decision making processes and continue to strive to maintain integrity and high scientific standards.

\section{Acronyms List: \\ COPE $=$ Committee on Publication Ethics \\ $\mathrm{GMC}=$ UK General Medical Council \\ MMR $=$ measles, mumps and rubella \\ WAME $=$ World Association of Medical Editors}

Conflicts of Interest: Dr. Selena Gray is Joint Editor of Journal of Public Health. Acknowledgements

Thanks to Ted Tulchinsky who provided timely feedback and encouragement to write this article, and the helpful comments of a thoughtful anonymous peer reviewer who extended the scope of the paper.

\section{About the Author:}

Selena Gray is Professor of Public Health at the University of the West of England, Bristol and Deputy Postgraduate Dean, Severn Deanery. After qualifying in medicine in Leeds, she worked in paediatrics in the UK and Saudi Arabia before training in public health medicine in the South West. She worked for as Clinical Adviser for the Regional NHS R\&D programme, and was a founding Director of the South West Public Health Observatory in 2000 before moving to the University of the West of England, Bristol (UK) in 2002.

She has had a longstanding involvement in public health training as Regional Adviser in Public Health, as Registrar of the Faculty of Public Health (2003-8), and is currently Joint Editor of the Journal of Public Health with Professor Gabriel Leung from the University of Hong Kong.

She has an interest in the wider determinants of health and has published over 50 articles in peer-reviewed journals, four invited book chapters and a wide variety of articles and letters across a wide range of public health related topics.

\section{REFERENCES}

1. Oxford University Press. Oxford Dictoriaries. Available from URL: http:// oxforddictionaries.com/definition/english/ethics (Accessed 18 August 2012). 
2. Rees M. Code of conduct and best practice guidelines for journal editors 2011. Committee on Publication Ethics (COPE). Available from URL: http:// publicationethics.org/ (Accessed 20 August 2012).

3. World Association of Medical Editors (WAME). Available from URL: http:// www.wame.org/ (Accessed 5 October 2012).

4. World Association of Medical Editors (WAME). Conflict of interest in peer reviewed journals. Available from URL: http://www.wame.org/conflict-ofinterest-in-peer-reviewed-medical-journals (Accessed 5 October 2012).

5. ten Have M, Beaufort ID, Mackenbach JP, van der Heide A. An overview of ethical frameworks in public health: can they be supportive in the evaluation of programs to prevent overweight? BMC Public Health. 2010;10:638.

6. Kass NE. An ethics framework for public health. Am J Public Health. 2001; 911:776-82.

7. Childress JF, Faden RR, Gaare RD, Gostin LO, Kahn J, Bonnie RJ, et al. Public health ethics: mapping the terrain. J Law Med Ethics. 2002;30:170-8.

8. Public Health Leadership Society: Principles of the ethical practice of public health. 2.2 edition. 2002. p.11. Available from URL: http://www.phls.org/ home/section/3-26/ (Accessed 9 November 2012).

9. Nuffield Council on Bioethics. Public health: ethical issues. London: Nuffield Council on Bioethics; 2007.

10. European Public Health Ethics Network. Public policies law and bioethics: a framework for producing public health policy across the European Union. EuroPHEN; 2006.

11. Tannahill A. Beyond evidence-to ethics: a decision-making framework for health promotion, public health and health improvement. Health Promot Int. 2008;23:380-90.

12. Coughlin SS. Ethical issues in epidemiologic research and public health practice. Emerg Themes Epidemiol. 2006;3:16.

13. Medical Research Council London. Ethics and research guidance. MRC. http:// www.mrc.ac.uk/Ourresearch/Ethicsresearchguidance/index.htm (Accessed 21 August 2012).

14. National Institutes of Health. Ethical Guidelines \& Regulations. NIH. Available from URL: http://grants.nih.gov/grants/policy/hs/ethical_guidelines.htm (Accessed 20 August 2012).

15. Thomson Reuters. The Thomas Reuters impact factor. Available from URL: http://thomsonreuters.com/products_services/science/free/essays/impact_ factor/ (Accessed 19 August 2012).

16. Wakefield AJ, Murch SH, Anthony A, Linnell J, Casson DM, Malik M, et al. Ileal-lymphoid-nodular hyperplasia, non-specific colitis, and pervasive developmental disorder in children. Lancet. 1998;351:637-41.

17. Horton A. A statement by the editors of The Lancet. Lancet. 2004;363:820-1.

18. The editors of the Lancet. Retraction-Ileal-lymphoid-nodular hyperplasia, non-specific colitis, and pervasive developmental disorder in children. Lancet. 2010;375:445. 
19. Godlee F, Smith J, Marcovitch H. Wakefield's article linking MMR vaccine and autism was fraudulent. Editorial. BMJ. 2011;342:c7452.

20. Deer B. Secrets of the MMR scare. How the case against the MMR vaccine was fixed. BMJ. 2011;342:c5347.

21. General Medical Council. Dr Andrew Jeremy WAKEFIELD Determination on Serious Professional Misconduct (SPM) and sanction. London: General Medical Council; 24 May 2010. Available from URL:http://www.gmc-uk.org/ Wakefield_SPM_and_SANCTION.pdf_32595267.pdf (Accessed 21 August 2012).

22. Pilkington PA, Gray S, Gilmore AB. Health impacts of exposure to second hand smoke (SHS) amongst a highly exposed workforce: survey of London casino workers. BMC Public Health. 2007;7:257

23. Steckler A, McLeroy KR. The importance of external validity. Am J Public Health. 2008;98:9-10.

24. CONSORT Transparent Reporting of Trials. Statement. Available from URL: http://www.consort-statement.org/home/ (Accessed 6 October 2012).

25. PRISMA Transparent Reporting of Systematic Reviews and Meta-analyses. Statement. Available from URL: http://www.prisma-statement.org/ (Accessed 6 October 2012).

26. Dickersin K, Chalmers I. Recognising, investigating and dealing with incomplete and biased reporting of clinical research: from Francis Bacon to the World Health Organisation. JLL Bulletin: Commentaries on the history of treatment evaluation. 2010. Available from URL: http://www.jameslindlibrary. org/illustrating/articles/recognising-investigating-and-dealing-withincomplete-and-biase (Accessed 21 August 2012).

27. American Academy Of Pediatrics Committee on Fetus and Newborn. Controversies concerning vitamin K and the newborn. Pediatrics. 2003;112:191-2.

28. Smith R. Commentary. Screening for future cardiovascular disease using age alone: reflections on a paper peer-reviewed as both "radical" and “unsurprising”. J Med Screening. 2011;18:113-4.

29. Wald NJ, Simmonds M, Morris JK. Screening for future cardiovascular disease using age alone compared to multiple risk factors and age. PLoS One. 2011;6:e18742.

30. Global Forum for Health Research. Available from URL: http://www. globalforumhealth.org/ (Accessed 20 Aug 2012).

31. Centers for Disease Control and Prevention (CDC) Spina bifida and anencephaly before and after folic acid mandate-United States, 1995-1996 and 19992000. MMWR Morb Mortal Wkly Rep. 2004;53:362-5.

32. Cohen D. The truth about sports drinks. BMJ. 2012;345:e4737.

33. Cohen D, Carter P. WHO and the pandemic flu 'conspiracies. BMJ. 2010; 340:c2912

34. Chan M. WHO response to article on conflicts of interest. BMJ 2010;340:c2912.

35. Evans MR.The swine flu scam? J Public Health. 2010;32:296-7. 
36. Jefferson T, Jones MA, Doshi P, Del Mar CB, Heneghan CJ, et al. Neuraminidase inhibitors for preventing and treating influenza in healthy adults and children. Cochrane Database Syst Rev. 2012;1:CD008965.

37. Tong EK, Glantz SA. Tobacco industry efforts undermining evidence linking secondhand smoke with cardiovascular disease Circulation. 2007;116:184554.

38. Smith R. Reed-Elsevier's hypocrisy in selling arms and health. J R Soc Med.2007;100:114-5.

39. Stafford T. Lessons from the Campaign against Elsevier. "We won, but how did we win?" ACME: An International E-Journal for Critical Geographies 2009;8:494-504.

40. The cost of knowledge. Available from URL: http://gowers.files.wordpress. com/2012/02/elsevierstatementfinal.pdf (Accessed 20 August 2012).

41. Smith R. The Trouble with Medical Journals. London: Royal Society of Medicine Press; 2007.

42. Northridge ME, McLeroy KR, Haviland ML, Johnson NJ, Benjamin GC. Editorial independence at the journal. Am J Public Health. 2005;95:377-9.

43. Northridge ME, McLeroy KR, Haviland ML. Essential tensions in the journal. Am J Public Health 2004;94:11-13.

44. No Authors. Demystifying peer review. Nat Cell Biol. 2010;12:413.

45. Lovejoy TI, Revenson TA, France CR. Reviewing manuscripts for peer review journals: a primer for novice and seasoned reviewers. Ann Behav Med. 2011; 42:1-13.

46. Simons-Morton B, Abraido-Lanza AF, Bernhardt JM, Schoenthaler A, Schnitzer A, Allegrante JP. Demystifying peer review. Health Educ Behav. 2012;39:3-7.

47. Committee on Publication Ethics (COPE). Plagiarism. Available from URL: http://publicationethics.org/category/keywords/plagiarism (Accessed 20 August 2012).

48. Godlee F. Helping institutions tackle research misconduct. Editorial. BMJ. 2012;345:e5402.

49. Wager E, Kleinert S, on behalf of COPE Council. Cooperation between research institutions and journals on research integrity cases: guidance from the Committee on Publication Ethics (COPE). 5 March 2012. Available from URL: www.publicationethics.org (Accessed 21 August 2012). 